\title{
A study on the menstruation of Korean adolescent girls in Seoul
}

Jin Chul Lee, M.D.', Byung Keun Yu, M.D.', Jung Hye Byeon, M.D.', Kee-Hyoung Lee, M.D. ${ }^{1}$ J Jung Hye Min, M.D. ${ }^{2}$, Sang Hee Park, M.D.

Department of ${ }^{1}$ Pediatrics, Korea University School of Medicine, ${ }^{2}$ Department of Pediatrics, Hongik Hospital, Seoul, Korea

Received: 15 September 2010, Revised: 19 November 2010 Accepted: 31 January 2011

Corresponding author: Sang Hee Park, M.D.

Department of Pediatrics, Korea University School of Medicine, Anam-dong 5-ga, Seongbuk-gu, Seoul 136-701, Korea

Tel: +82-2-920-5695, Fax: +82-2-922-7476

E-mail: shpark@kumc.or.kr

Copyright (C 2011 by The Korean Pediatric Society
Purpose: Westernized eating habits have been associated with earlyage menstruation, which increases the incidence of dysmenorrhea and premenstrual syndrome among adolescent girls. We therefore surveyed changes in menarche timing and the general menstrual characteristics of adolescent girls in Seoul, Korea.

Methods: We surveyed 538 teenage girls who visited our hospital between July and November 2007. Items explored included age at menarche, general menstrual characteristics, occurrence of premenstrual syndrome and treatment thereof, and an association between present dysmenorrhea and a family history of the condition. Results: Average age at menarche was 12.6 years, with 29\% ( $n=156)$ subjects beginning menstruation at age 12 years. The prevalence of dysmenorrhea was $82 \%(n=435)$. The main symptoms were abdominal (53.2\%) and lower back pain (34.2\%), and 15.2\% of girls who experienced such symptoms required medication. Present dysmenorrhea, and a family history thereof, were statistically correlated $(P<0.05)$. In addition, $58.8 \%$ ( $n=316)$ of teenage girls had symptoms of premenstrual syndrome. The most frequent psychological symptoms were fatigue $(36.4 \%)$ and nervousness $(38.7 \%)$, whereas the most common physical symptom was menstrual cramps (46.5\%). Most subjects $(87.6 \%)$ tolerated the symptoms of premenstrual syndrome without medication; $11.4 \%$ took medicines including painkillers; but only $0.1 \%$ of subjects visited a doctor.

Conclusion: The average age at menarche in Korean girls was 12.6 years, thus younger than in the past. Most teenage girls experienced dysmenorrhea and premenstrual syndrome, but few consulted a doctor. Organized treatment plans are required to manage menstrual problems in teenage girls.

Key words: Adolescent, Menarche, Dysmenorrhea, Premenstrual syndrome

This is an open-access article distributed under the terms of the Creative Commons Attribution Non-Commercial License (http://creativecommons.org/licenses/by$\mathrm{nc} / 3.0 /$ ) which permits unrestricted non-commercial use, distribution, and reproduction in any medium, provided the original work is properly cited. 


\section{Introduction}

Menarche is an important event in the life of an adolescent girl, most of whom experience menarche before the age of 16 years. During this period, girls go through physical changes that are important in the psychological perception of sexual identity and that considerably influence mental maturity ${ }^{1-3)}$. Historically, the age at menarche has gradually decreased, by about 4 months in every 10year interval ${ }^{4)}$. Over the last century, the age at menarche has fallen by 2 to 4 months every 10 years in the USA and Europe. Recently, mean age at menarche has stabilized at around 12 to 13 years of age, and has even increased in several countries, including Germany and the United Kingdom ${ }^{5,6)}$. In Korea, age at menarche has declined, from 15 to 17 years in the 1960 s to around 14 years in the 1980 s, and to 12.8 years in the 1990 s, because of consumption of an increasingly Westernized $\operatorname{diet}^{7}$. As age at menarche declined, the number of adolescents suffering from menstrual disorders such as dysmenorrhea and premenstrual syndrome has increased. Although $75 \%$ of girls in late puberty experience menstrual disorders, many hesitate to consult medical professionals, as they find open discussion of their problems embarrassing. Thus, such girls may not be adequately diagnosed or treated and may experience reproductive physiology problems during adulthood ${ }^{8)}$. We therefore surveyed current changes in the age of menarche in Korean adolescents. We also evaluated general menstruation patterns, the incidence of common menstrual disorders, and the means used to cope with such problems.

\section{Materials and methods}

\section{Subjects}

The subjects of this study were 538 physically healthy, Korean, middle-high school students aged 14 to 18 years (mean age, 16.1 years) who visited our Pediatrics clinic in Seoul for health examinations between July and November, 2007.

\section{Questionnaire}

Subjects, and their parents, were asked to complete an anonymous questionnaire containing 16 items. We surveyed all of age; basic personal details; age at menarche; general features of menstruation; dysmenorrhea and premenstrual syndrome prevalence; and relevant family history.

\section{Statistical analysis}

The $\chi^{2}$-test was used to determine the correlation between present dysmenorrhea and a family history thereof. All statistical analyses were performed using SPSS ver. 12.0 (SPSS Inc., Chicago, IL, USA).
A $P$ value $<0.05$ was considered statistically significant.

\section{Results}

\section{Change in age at menarche}

The mean age of all respondents was 16.1 years. Of the 538 subjects, 93.1\% ( $\mathrm{n}=501)$ reported that they had experienced menarche, $1.1 \%(n=6)$ reported they had not, and 5.8\% $(n=31)$ could not remember. Age at menarche was 12 years in $29.0 \%$ of respondents ( $n=156), 13$ in 23.8\% ( $n=128), 11$ in 20.1\% ( $n=108)$, and 14 in $13.2 \%(n=71)$. Mean age at menarche was 12.6 years (Table 1$)$.

\section{Menstruation pattern}

Of all respondents, 32.3\% ( $\mathrm{n}=173)$ reported that the menstrual cycle was irregular. Cycle length was 26 to 30 days in $28.6 \%$ ( $n=154)$, 21 to 25 days in $11.3 \%$ ( $n=61), 31$ to 35 days in $12.1 \%(n=65)$, and 15 to 20 days in $5.6 \%(n=30)$. The duration of menstruation was 5 to 6 days in $51.1 \%$ ( $\mathrm{n}=275), 3$ to 4 days in $22.9 \%$ ( $\mathrm{n}=123)$, and 7 to 8 days in $21.9 \%$ ( $\mathrm{n}=118$ ). When we assorted respondents by the number of pads used per day, with menstrual flow defined as "small", "moderate" and "large" upon use of $\leq 3,4-7$, and $\geq 8$ pads, respectively, we found that $70.1 \%$ ( $n=377)$ of subjects had "moderate" menstruation (Table 2).

\section{Premenstrual syndrome}

We found that $47.6 \%(n=256)$ of respondents had not heard of premenstrual syndrome, $32.3 \%(n=174)$ were familiar with the syndrome but lacked accurate knowledge thereof, whereas $19.3 \%$ ( $n=104)$ were well-informed. In contrast, when subjects were individually asked whether they had experienced symptoms of premenstrual syndrome, $47.7 \%(\mathrm{n}=251)$ reported such events occasionally, $12.5 \%(\mathrm{n}=67)$ replied that they always experienced symptoms, and 39.8\% ( $\mathrm{n}=214)$ said they had never experienced problems (Table 3). The most common psychological symptoms of

Table 1. Age at Menarche

\begin{tabular}{cc}
\hline Variable & No. $(\%)$ \\
\hline Age $(\mathrm{yr})$ & \\
$<10$ & $15(2.8)$ \\
11 & $108(20.1)$ \\
12 & $156(29.0)$ \\
13 & $128(23.8)$ \\
14 & $71(13.2)$ \\
15 & $20(3.7)$ \\
$>15$ & $3(0.6)$ \\
Total & $501(100.0)$ \\
Mean $(\mathrm{yr})$ & 12.6
\end{tabular}


premenstrual syndrome were nervousness (38.7\%, 208 subjects), fatigue (36.4\%, $\mathrm{n}=196)$, and sleepiness $(28.4 \%, \mathrm{n}=153)$; although $32.7 \%$ of subjects ( $\mathrm{n}=176)$ reported no such symptoms. The most frequent physical symptoms of premenstrual syndrome were abdominal cramps (46.5\%, 250 subjects), low back pain (28.4\%, $\mathrm{n}=135)$, acne (21.4\%, $\mathrm{n}=115)$, and breast pain (17.5\%, $\mathrm{n}=94)$; although $23.6 \%$ of subjects ( $\mathrm{n}=127)$ reported no such symptoms (Table 4).

When subjects were asked how they coped with symptoms, $87.6 \%$ $(n=276)$ reported that they did not access medication or treatment,

Table 2. Characteristics of Menstruation

\begin{tabular}{|c|c|}
\hline Variable & $(\%)$ \\
\hline \multicolumn{2}{|l|}{ Interval (day) } \\
\hline Irregular & 32.2 \\
\hline$\leq 14$ & 4.3 \\
\hline $15-20$ & 5.6 \\
\hline $21-25$ & 11.3 \\
\hline $26-30$ & 28.6 \\
\hline $31-35$ & 12.1 \\
\hline $36-40$ & 2.2 \\
\hline $41-45$ & 0.7 \\
\hline$\geq 46$ & 0.2 \\
\hline Subtotal & 97.2 \\
\hline \multicolumn{2}{|l|}{ Duration (day) } \\
\hline $1-2$ & 0.4 \\
\hline $3-4$ & 22.9 \\
\hline $5-6$ & 51.1 \\
\hline $7-8$ & 21.9 \\
\hline$\geq 9$ & 1.9 \\
\hline Subtotal & 98.2 \\
\hline \multicolumn{2}{|c|}{ Amount (sanitary pad usage) (No.) } \\
\hline $\operatorname{Low}(\leq 3)$ & 24.3 \\
\hline Moderate (4-7) & 70.1 \\
\hline Heavy $(\geq 8)$ & 3.9 \\
\hline Subtotal & 98.3 \\
\hline
\end{tabular}

Table 3. General Knowledge about Premenstrual Syndrome (PMS)

\begin{tabular}{lc}
\hline Variable & $(\%)$ \\
\hline Recognition & \\
Already knew of PMS & 19.3 \\
Had heard about PMS, but did not have & 33.4 \\
$\quad$ accurate knowledge accurate knowledge & \\
Did not know of PMS & 47.6 \\
Subtotal & 100.0 \\
Experience & \\
Never & 39.8 \\
Sometimes & 47.7 \\
Always & 12.5 \\
Subtotal & 100.0 \\
\hline
\end{tabular}

and only $11.4 \%(n=36)$ took over-the-counter medications, such as pain killers, purchased from a pharmacy. Only $0.1 \%$ of subjects $(n=1)$ visited a hospital and $0.4 \%(n=2)$ attended an Oriental clinic (Table 5).

\section{Dysmenorrhea}

We found that $82 \%(n=435)$ of female students reported dysmenorrhea, 1 to 2 days in duration in $38.3 \%(n=206), \leq 24$ hours in $25.5 \%$ ( $\mathrm{n}=137), 2$ to 3 days in $12.5 \%(\mathrm{n}=67)$, and $\geq 3$ days in $3.5 \%$ $(\mathrm{n}=19)$. In most subjects, the principal symptom was mild pain that did not impact on normal daily life; painkillers were not needed $(65.6 \%, n=353)$. However, $0.9 \%$ of subjects $(n=5)$ had severe pain not relieved by pain killers, and other symptoms (Table 6). The most common dysmenorrhea problems were abdominal cramp $(53.2 \%$, 286 subjects), low-back pain (34.2\%, n=184), fatigue (21.6\%, $n=116$ ), and nervousness $(22.1 \%, \mathrm{n}=119)$ (Table 7$)$.

When we examined the relationship between dysmenorrhea and a family history thereof, we found that $53.9 \%$ of subjects $(n=229)$

Table 4. Symptoms of Premenstrual Syndrome

\begin{tabular}{lc}
\hline Variable & $(\%)$ \\
\hline Psychological symptom & \\
No symptom & 32.7 \\
Fatigue & 36.4 \\
Sleepiness & 28.4 \\
Anger & 16.9 \\
Depression & 21.2 \\
Nervousness & 38.7 \\
Aggression & 10.4 \\
Sleeplessness & 3.4 \\
Irritability & 5.4 \\
Physical symptom & \\
No symptom & 23.6 \\
Abdominal pain & 46.5 \\
Low-back pain & 28.4 \\
Breast pain & 17.5 \\
Breast enlargement & 7.3 \\
Acne & 21.4 \\
Decreased appetite & 7.6 \\
Weight gain & 7.3 \\
Weight loss & 1.5 \\
\hline
\end{tabular}

Table 5. Management of Premenstrual Syndrome

\begin{tabular}{lr}
\hline Variable & $(\%)$ \\
\hline None & 87.6 \\
Medication from a pharmacy & 11.4 \\
Hospital visit & 0.1 \\
Visit to an oriental clinic & 0.6 \\
Total & 100.0
\end{tabular}


Table 6. Characteristics of Dysmenorrhea

\begin{tabular}{lc}
\hline Variable & $(\%)$ \\
\hline Duration (day) & \\
No dysmenorrhea & 18.0 \\
$\leq 1$ & 25.5 \\
$1-2$ & 38.3 \\
$2-3$ & 14.7 \\
$\geq 3$ & 3.5 \\
Severity & \\
No dysmenorrhea & 18.0 \\
Mild pain* & 65.6 \\
Moderate pain ${ }^{\dagger}$ & 14.3 \\
Severe pain with other symptoms ${ }^{\ddagger}$ & 1.2 \\
\hline${ }^{*}$ No medication required. ${ }^{\dagger}$ Medication required and sometimes absent from \\
school. ${ }^{\ddagger}$ Medication ineffective.
\end{tabular}
school. " Medication ineffective.

Table 7. Symptoms of Dysmenorrhea

\begin{tabular}{lc}
\hline Variable & $(\%)$ \\
\hline No dysmenorrhea & 18.4 \\
Abdominal pain & 53.2 \\
Low-back pain & 34.2 \\
Nervousness & 22.1 \\
Fatigue & 21.6 \\
Dizziness & 10.4 \\
Nausea & 7.1 \\
Diarrhea & 5.8 \\
Skin rash & 3.0 \\
\hline
\end{tabular}

Table 8. Relationship between Present Dysmenorrhea and a Family History of the Condition

\begin{tabular}{|c|c|c|c|c|}
\hline \multirow{2}{*}{ Variable } & \multicolumn{2}{|c|}{ Family history (No.) } & \multirow{2}{*}{ Total } & \multirow{2}{*}{$P$ value } \\
\hline & Yes & No & & \\
\hline Dysmenorrhea & & & & 0.031 \\
\hline Yes & 229 & 196 & 425 & \\
\hline No & 40 & 56 & 96 & \\
\hline Total & 269 & 252 & 521 & \\
\hline
\end{tabular}

had dysmenorrhea shared with a family member (mother or sister), whereas 46.1\% ( $\mathrm{n}=196$ ) did not have such a family member (Table 8). Statistical analysis showed a significant correlation between present dysmenorrhea and a family history thereof $(P<0.05)$.

\section{Discussion}

Age at menarche is affected by various factors, including genetic and socio-economic parameters, nutritive state, psychological variables, individual physical structure, geography, weather, disease, and exercise, and may be a practical indicator of the maturity and health of both individuals and groups ${ }^{9,10)}$. For example, age at menarche has been found to be lower in tropical than in temperate regions ${ }^{11}$. Menarche has been reported to be more frequent in summer and winter than in spring and autumn ${ }^{12)}$, and to occur more commonly in spring and summer than in autumn and winter ${ }^{13)}$.

However, reports on associations between age at menarche and season have not yielded consistent results. Compared with ordinary students, age at menarche has been found to be generally later in students (ballerinas or athletes) who engage in intensive physical activity during childhood, and earlier in students under psychological stress resulting from family discord or placement in an orphanage ${ }^{14)}$. In addition, age at menarche has been reported to be closely correlated with parental educational level and occupation, being delayed by about 8 months when parents are poorly educated (unschooled, or mere high school graduates) compared to parents who are better educated (2-year college or higher-level graduates), and by about 6 months when parents are unemployed, or farmers, compared to parents working as civil servants or teachers ${ }^{15)}$.

Recently, however, age at menarche has fallen regardless of region or race because of improvements in nutrition and physical growth, and changes in the socio-economic environment ${ }^{16)}$. Thus, age at menarche is not fixed, but rather varies among population groups and over time ${ }^{17)}$. For example, surveys of English adolescents in 1940 to 1960, during and after World War II, showed that age at menarche decreased by 3 to 4 months every 10 years ${ }^{18}$. In Western countries, age at menarche has fallen by 2 to 3 months every 10 years over the last 150 years ${ }^{1920)}$. In the USA and Europe, age at menarche was 17 years in the 19th century, 14.7 years in $1877^{21}$, and 12.2 to 12.9 years in recent years ${ }^{22-24)}$.

In Korea, research on the age of menarche commenced in $1923^{25}$, and has continued since that time. Mean age at menarche has generally decreased; from 14.8 years in 1962 to about 14 years in $1973,14.4$ years in 1979, 13.4 years in 1986, 12.5 years in 1988, and $12.4 \pm 1.1$ years in $1993^{26}$. Regionally, age at menarche was 1 year earlier in Seoul than in other regions of Korea ${ }^{27)}$. Age at menarche was 16.2 years in urban women and 16.3 years in rural women ${ }^{28)}$, and 13.4 years in women living in large cities and 13.7 years in those residing in small cities or rural areas ${ }^{29}$. We found that the mean age at menarche was 12.6 years, confirming the recent trend toward earlier menarche in Koreans. Also, age at menarche did not differ greatly from that in European nations or the USA. However, our sampling area was confined to Seoul, and our results may thus not be representative of the entire Korean population.

When we surveyed general menstruation patterns, we found that, contrary to our expectations, many female students had irregular menstrual cycles. Moreover, increasingly earlier menarche was associated with an elevated prevalence of menstrual disorders 
including dysmenorrhea and premenstrual syndrome, and with the severity of these conditions. Dysmenorrhea, evident at the beginning of menstruation or just prior to menstruation, is categorized by presence of lower abdominal pain accompanied by gastrointestinal and neurological symptoms. We found that most students experienced dysmenorrhea during menstruation, although pain was mild. However, about $15 \%$ of students complained of severe symptoms, requiring use of painkillers and/or absence from school. In contrast, a previous study ${ }^{30)}$ found that only $4 \%$ of subjects suffered disrupted school attendance because of dysmenorrhea, although another report found that $16 \%$ of subjects were in this category $^{31)}$. Premenstrual syndrome, another common menstrual disorder that usually features mood swings occurring about 1 week before menstruation, is experienced by most menstruating women, particularly those 20 to 40 years of age. The symptoms vary among individuals and may differ from cycle to cycle. The principal problems include headache, nausea, weight gain, breast tenderness, abdominal distention, fatigue, change in appetite, anxiety, irritation, and depression. These symptoms usually appear 7 to 10 days before menstruation and disappear several hours after commencement of menstruation ${ }^{8)}$. The symptoms are subjective, and diagnostic tools including a premenstrual assessment form (PAF) have been formalized, but it continues to be difficult to objectively diagnose the syndrome because of the absence of accurate criteria. The PAF is composed of 10 questions addressing mood swing, water retention, and pain. Each question is answered on a 6-point scale ("no change," "very little change," "mild change," "moderate change," "severe change," and "extreme change"), with a higher score indicating more severe disturbance. Dysmenorrhea has been associated with premenstrual syndrome ${ }^{32)}$, although the mechanism of interaction has not been determined. Other menstrual disorders include abnormal and dysfunctional uterine bleeding. As such problems were not explored in our survey, additional research on menstrual disorders common among adolescents is required.

We found that the major symptoms of premenstrual syndrome were nervousness, depression, inertia, abdominal cramps, and lower abdominal pain, similar to previous findings ${ }^{33)}$. We also surveyed how our adolescent students perceived and coped with premenstrual syndrome. We found that more than half experienced premenstrual syndrome but could not accurately self-diagnose the condition, and some students did not recognize that they were experiencing the symptoms. Moreover, whereas many students suffered from premenstrual syndrome, only $0.1 \%$ consulted medical specialists; most simply endured the problems. This suggests that systematic approaches to treatment of menstrual disorders in adolescence should be developed, featuring a detailed clinical history-taking, counseling, and a treatment plan.

Although adolescent menstrual disorders have been actively studied in Korea, only a few reports have assessed the association between present dysmenorrhea and a family history thereof. When we explored this association, we found that $53.9 \%$ of students who had a family member (mother or sister) with dysmenorrhea also experienced the condition; this rate was higher than the values of $51.1 \%^{30)}$ and $41.1 \%{ }^{34)}$ previously reported. Moreover, we found that the correlation between present dysmenorrhea and a family history thereof was statistically significant $(P<0.05)$. Thus, a detailed family history of dysmenorrhea must be taken when a systematic therapeutic approach to dysmenorrhea in adolescents is envisaged.

Our study had several limitations. First, all study subjects were middle-high school students in Seoul, and our results thus cannot be automatically generalized to students in other regions of Korea. A large-scale nationwide survey is required, and data on age at menarche by birth cohort are needed. Second, premenstrual syndrome includes both physical and psychological symptoms evident before menstruation begins; however, most study subjects were not well acquainted with premenstrual syndrome per se. This means that our survey of symptom memory may have been influenced by information bias. In other words, those who did not understand "premenstrual syndrome" may not have given valid responses to the relevant questions.

Our study was cross-sectional in design, and the data are useful to aid understanding of current changes in age at menarche among Korean girls. Further, we canvassed the methods by which adolescent students coped with menstrual disorders. Our results suggest that pediatricians should accurately explain the normal menstrual cycle to adolescent patients, take detailed clinical histories, and perform physical examinations and order appropriate tests to determine causes of menstrual disorders in such patients, so that problems may be appropriately treated.

\section{References}

1. Cochrane R. The menarche. Practitioner 1993;237:431-4.

2. Moffitt TE, Caspi A, Belsky J, Silva PA. Childhood experience and the onset of menarche: a test of a sociobiological model. Child Dev 1992;63:47-58.

3. Neinstein LS. Menstrual problems in adolescents. Med Clin North Am 1990;74:1181-203.

4. Tanner JM. Growth at adolescence. Oxford: Blackwell Scientific Publications, 1955.

5. Rees M. Menarche when and why? Lancet 1993;342:1375-6.

6. Pelz L. Menarcheal age in East German girls. Acta Paediatr 1992;81:9467. 
7. Hong $\mathrm{CH}$, Rho HO, Song $\mathrm{SH}$. The sexual maturity rating of adolescent boys and girls in Korea. J Korean Pediatr Soc 1994;37:193-8.

8. Choi IJ. Menstrual disorders in adolescence. J Korean Soc Pediatr Endocrinol 2008;13:15-20.

9. Zacharias L, Wurtman RJ, Schatzoff M. Sexual maturation in contemporary American girls. Am J Obstet Gynecol 1970;108:833-46.

10. Henneberg M, Louw GJ. Average menarcheal age of higher socioeconomic status urban Cape coloured girls assessed by means of status quo and recall methods. Am J Phys Anthropol 1995;96:1-5.

11. Saar E, Shalev C, Dalal I, Sod-Moriah UA. Age at menarche: the influence of environmental conditions. Int J Biometeorol 1988;32:33-5.

12. Reymert ML, Jost H. Further data concerning normal variability of the menstrual cycle during adolescence and factors associated with age of menarche. Child Dev 1947;18:169-79.

13. Matsumoto S, Ozawa M, Nogami Y. Menstrual cycle in puberty. Gunma J Med Sci 1963;12:119-43.

14. Graber JA, Brooks-Gunn J, Warren MP. The antecedents of menarcheal age: heredity, family environment, and stressful life events. Child Dev 1995;66:346-59.

15. Park GC. Epidemiologic investigation of menarche and postmenarcheal menstrual patterns in rural area. Korean J Obstet Gynecol 1988;31:135774.

16. Chang K. Seasonal distribution of menarche in Hong Kong school girls. Far East Med J 1976;3:203-6.

17. Zacharias L, Wurtman RJ. Age at menarche. Genetic and environmentalinfluences. N Engl J Med 1969;280:868-75.

18. Tanner JM. Growth at adolescence. 2nd ed. Oxford: Blackwell Scientific Publications, 1962;22.

19. Okasha M, McCarron P, McEwen J, Smith GD. Age at menarche: secular trends and association with adult anthropometric measures. Ann Hum Biol 2001;28:68-78.

20. Marshall WA, Tanner JM. Puberty. In: Falkner FT, Tanner JM, editors. Human growth: a comprehensive treatise. 2nd ed. New York: Plenum Press, 1986:171-209.

21. Grumbach MM. Styne DM. Puberty: ontogeny, neuroendocrinology, physiology, and disorders. In : Williams RH, Larsen PR, editors. Williams textbook of endocrinology. 10th ed. Philadelphia: WB Saunders Co,
2003;668-93.

22. Anderson SE, Dallal GE, Must A. Relative weight and race influence average age at menarche: results from two nationally representative surveys of US girls studied 25 years apart. Pediatrics 2003;111(4 Pt 1):84450.

23. Parent AS, Rasier G, Gerard A, Heger S, Roth C, Mastronardi C, et al. Early onset of puberty: tracking genetic and environmental factors. Horm Res 2005;64 Suppl 2:41-7.

24. Rosenfield RL, Bachrach LK, Chernausek SD, Gertner JM, Gottschalk M, Hardin DS, et al. Current age of onset of puberty. Pediatrics 2000; 106:622-3.

25. Lee YC. A study of menarche in Korean female adolescent students. Korean J Med Hist 1923;101.

26. Kim HS, Kim JY, Shin YK, Park SH, Tockgo YC. A study on menarchel age and monthly incidence of school girls in ansan. J Korean Pediatr Soc 1997;40:458-63.

27. Min BK, Lee KH, Kim HS. A Study on the age at menarche and emotional response toward menarche among Korean adolescent schoolers, aged 12 through 21 inclusive (1978). Off J Res Med Sci Korea 1979;11:4358.

28. Kim JS. A study on mensturation of Korean female. J Asian Women 1962;1:115-39.

29. Ko KS, Yoon DR. A study on the menarche and the menstrual patterns of high-school girls in seoul. Korean J Obstet Gynecol 1986;29:239-51.

30. Kim MY, Jung MS. Degree of dysmenorrhea and self-management of dysmenorrhea in the high-school girl-students. J Korean Acad Womens Health Nurs 2000;6:413-26.

31. Kim EZ. Premenstrual syndrome and personality. J Nurs Acad Soc 1988; 18:80-93.

32. Paulson MJ. Psychological concomitants of premenstrual tension. Am J Obstet Gynecol 1961;81:733-8.

33. Kim J, Ryu SY. The prevalence of premenstrual syndrome and its related factors among high school girls. J Korean Soc Matern Child Health 2006; 10:11-20.

34. Choi KH. Dysmenorrhea pattern and self-management in the middle and high school girl students [dissertation]. Daegu: Kyungpook National University, 1998. 